\title{
miR-4262 regulates chondrocyte viability, apoptosis, autophagy by targeting SIRT1 and activating PI3K/AKT/mTOR signaling pathway in rats with osteoarthritis
}

\author{
WENCAI SUN ${ }^{1}$, YINTAI $\mathrm{LI}^{2}$ and SUIZHUAN WEI ${ }^{3}$ \\ ${ }^{1}$ Department of Orthopaedics, The Third Hospital Affiliated to Qiqihar Medical College, \\ Qiqihar, Heilongjiang 161006; Departments of ${ }^{2}$ Rehabilitation and ${ }^{3}$ Orthopaedics, \\ Baoji Traditional Chinese Medicine Hospital, Baoji, Shaanxi 721000, P.R. China
}

Received May 16, 2017; Accepted October 16, 2017

DOI: 10.3892/etm.2017.5444

\begin{abstract}
The present study aimed to investigate the effect and underlying mechanism of microRNA (miR)-4262 in the development of osteoarthritis (OA) in rats. Primary chondrocytes were separated from Sprague-Dawley rats and then treated with tumor necrosis factor- $\alpha$ (TNF- $\alpha)$. The level of miR-4262 was detected in TNF- $\alpha$-treated chondrocytes, and then the miR-4262 or its target gene sirtuin type 1 (SIRT1) level was overexpressed, or knocked down. Furthermore, cell viability, cell apoptosis, cell autophagy and matrix synthesis, as well as the expressions of proteins associated with the phosphoinositide 3-kinase (PI3K)/protein kinase B (AKT)/mammalian target of rapamycin (mTOR) signaling pathway were detected. miR-4262 was significantly overexpressed in TNF- $\alpha$-treated chondrocytes compared with untreated cells $(\mathrm{P}<0.05)$. TNF- $\alpha$ treatment or miR-4262 overexpression significantly decreased cell viability, autophagy-related proteins levels and matrix synthesis-related proteins levels, as well as increased the apoptotic rate in chondrocytes $(\mathrm{P}<0.05)$. Overexpression of SIRT1 significantly increased cell viability, autophagy-related proteins levels and matrix synthesis-related proteins levels, as well as decreased the apoptotic rate in TNF- $\alpha$-treated chondrocytes $(\mathrm{P}<0.05)$. In addition, the effects of miR-4262 on cell viability, cell apoptosis, cell autophagy and matrix synthesis were inhibited by SIRT1 $(\mathrm{P}<0.05)$. Furthermore, upregulated miR-4262 remarkably increased the expressions of phosphorylated (p)-PI3K, p-AKT and p-mTOR $(\mathrm{P}<0.05)$ in TNF- $\alpha$ treated chondrocytes. The present study revealed that the upregulation of miR-4262 may promote the
\end{abstract}

Correspondence to: Professor Suizhuan Wei, Department of Orthopaedics, Baoji Traditional Chinese Medicine Hospital, 43 Baofu Road, Baoji, Shaanxi 721000, P.R. China

E-mail: suizhuanwei06@126.com

Key words: miR-4262, osteoarthritis, cell autophagy, matrix synthesis, PI3K/AKT/mTOR signaling pathway occurrence and development of OA in rats by regulating cell viability, cell apoptosis, cell autophagy, and matrix synthesis. Furthermore, these roles of miR-4262 may be associated with PI3K/AKT/mTOR signaling pathway.

\section{Introduction}

Osteoarthritis (OA) is the most common arthritis characterized by a hallmark symptom of pain, even leads to disability (1). It is well-known that OA is caused by the combined effects of genetic, biological, and biomechanical factors (2). With the rise of obesity as well as an ageing population, the prevalence of OA is increasing (2). The quality of life of these population is poor in the end-stage of OA due to joint destruction (3). Currently, joint replacement is considered as an effective treatment for end-stage OA; however, high socioeconomic cost, poor functional outcomes and the limited lifespan of prostheses influence its application and efficacy $(4,5)$. Thus, it is imperative to search for new and effective intervention and therapy for OA.

Recently, microRNAs (miRNAs/miRs), small non-coding RNAs, play a significant regulatory role in oncogenesis through mediating target genes expressions (6). Increasing evidences suggest that miRNAs are widely involved in immune response, inflammation reaction, infection as well as cell metabolism, growth and migration $(7,8)$. Accumulating studies have focused on the potential roles of miRNAs in various diseases, such as autoimmune diseases (9), cardiovascular diseases (10), neurodegeneration diseases (11), and cancers (12). Thus, understanding the mechanisms of miRNAs in OA development may contribute to search for an effective treatment for this disease.

It has been shown that miR-4262 exerts the vital roles in a variety of tissues and cells. Previous study has suggested that miR-4262 participates in the development of acute lung injury through regulating the apoptosis of pulmonary endothelial cells (13). Zhang et al (14) and Lu et al (15) have demonstrated that miR-4262 exerts pro-proliferation effect in human cutaneous malignant melanoma cells and hepatocellular carcinoma cells. In addition, up-regulated miR-4262 can inhibit osteopontin-mediated cell invasion in osteosarcoma (16). 
Although the pathogenic effects of miR-4262 on several diseases have been disclosed, the role of miR-4262 in OA is still unclear.

Sirtuin type 1 (SIRT1), a mammalian homolog of silent information regulator 2 (Sir2), has been found to be a key regulator in the pathogenesis of OA (17). In chondrocytes, SIRT1 reduction may result in chondrocyte hypertrophy and cartilage matrix loss (17). Moreover, inhibition of SIRT1 induces chondrocyte apoptosis via modulating mitochondria-related apoptotic signals (18). It is also reported that disruption of SIRT1 in chondrocytes can accelerate OA progression under mechanical stress and during ageing in mice (19). Furthermore, activation SIRT1 can protect chondrocytes from tumor necrosis factor- $\alpha$ (TNF- $\alpha$ )-induced inflammatory effects, and SIRT1 activators may be explored as potential treatments for OA (20). Given the key role of SIRT1 in OA, we hypothesized that miR-4262 may play a key role in OA development via regulating SIRT1. In the present study, primary chondrocytes were separated, and OA cell model was induced by the treatment of TNF- $\alpha$. The level of miR-4262 was detected in TNF- $\alpha$-treated chondrocytes, and then the effects of aberrant expression of miR-4262 or its target gene SIRT1 on cell viability, cell apoptosis, cell autophagy, and matrix synthesis, as well as the expressions of proteins related to phosphoinositide 3-kinase (PI3K)/AKT/mammalian target of rapamycin (mTOR) signaling pathway were evaluated, aiming to investigate the effect and underlying mechanism of miR-4262 in OA.

\section{Materials and methods}

Isolation and culture of primary articular chondrocytes. Approval from the Ethics Committee of Animal Experimental Center of University, and all experiments were performed following the guidelines of the Institutional Animal Care and Use Committee. Six healthy Sprague-Dawley (SD) rats (200-250 g) were provided to isolate primary articular chondrocytes as previously described (21). In brief, the cartilage tissues from knee joints of rats were sliced into small pieces, and then digested with DMEM/F12 medium containing $100 \mathrm{U} / \mathrm{ml}$ penicillin, $100 \mu \mathrm{g} / \mathrm{ml}$ streptomycin, $10 \%$ fetal bovine serum (FBS), and $0.2 \%$ Type II collagenase for $24 \mathrm{~h}$ at $37^{\circ} \mathrm{C}$. Undigested cartilages were removed and primary chondrocytes were maintained in DMEM/F12 medium. The isolated chondrocytes were confirmed by the histological observation, and differentiation markers in chondrocytes, including collagen type 2 (Col2) and aggrecan, was detected by quantitative PCR (qPCR) analysis. OA model of chondrocytes was then induced by $20 \mathrm{ng} / \mathrm{ml}$ of TNF- $\alpha$ (PeproTech, Rocky Hill, NJ, USA). To evaluate the role of miR-4262 in OA, OA-chondrocytes were transfected with scramble (control of mimic), miR-4262 mimic, NC (control of inhibitor), miR-4262 inhibitor, pEX (control of pEX-SIRT1), pEX-SIRT1, siNC (control of si-SIRT1), or si-SIRT1 using Lipofectamine ${ }^{\circledR} 2000$ (Invitrogen; Thermo Fisher Scientific, Inc., Waltham, MA, USA). Cells with various treatments were exposed to $2 \mu \mathrm{M}$ rapamycin (RAPA, autophagic activator) to evaluate the cell autophagy. In addition, we performed similar autophagy tests in the presence or absence of lysosomal protease inhibitors E64d (1 mg/ml; Sigma-Aldrich; Merck KGaA, Darmstadt,
Germany) and pepstatin A (1 mg/ml; Sigma-Aldrich; Merck KGaA).

Cell viability assay. Chondrocytes $\left(5 \times 10^{3}\right.$ cells/well) were grown in 96-well plates and received the above various treatments for 0, 12, 24, 48 h. Cell Counting Kit-8 (CCK-8; Dojindo Laboratory, Kumamoto, Japan) was used to detect cell viability. Cells were treated with $10 \%$ WST- 8 for $4 \mathrm{~h}$ at $37^{\circ} \mathrm{C}$, then the absorbance at $450 \mathrm{~nm}$ was measured using a microplate reader (Molecular Devices, Sunnyvale, CA, USA).

TUNEL staining. After various treatments, cells apoptosis was performed using TUNEL staining (DeadEnd Fluorometric TUNEL System; Promega Corporation, Madison, WI, USA). In brief, $4 \%$ formaldehyde was used to fix cells at $4^{\circ} \mathrm{C}$ for $25 \mathrm{~min}$. After the equilibration for $10 \mathrm{~min}$ at room temperature, the cells were incubated with $\mathrm{TdT}$ reaction mix at $37^{\circ} \mathrm{C}$ for $1 \mathrm{~h}$. Afterwards, 2X SSC was added into cells for $15 \mathrm{~min}$, and then stained with DAPI solution for $5 \mathrm{~min}$ to visualize all nuclei.

$q P C R$ analysis. After various treatments, total RNAs was extracted using TRIzol (Invitrogen; Thermo Fisher Scientific, Inc.) and complementary DNA synthesis was carried out using miRNA specific primers (Invitrogen; Thermo Fisher Scientific, Inc.). The PCR primers for miR-4262 and U6 were commercially obtained from Applied Biosystems (Foster City, CA, USA). The primers for uncoordinated 51-like kinase 1 (ULK1), asparagine-linked glycosylation 5 (ALG5), Beclin-1, LC3II, type II collagen (COL2A1), aggrecan (ACAN), matrix metallo protease 13 (MMP-13), a disintegrin and metalloproteinase with thrombospondin motifs-5 (ADAMTS-5), SIRT1, and glyceraldehyde-3-phosphate dehydrogenase (GAPDH) are shown in Table I. The PCR parameters were set as follows: $95^{\circ} \mathrm{C}$ for $10 \mathrm{~min}, 40$ cycles of $94^{\circ} \mathrm{C}$ for $30 \mathrm{sec}, 58^{\circ} \mathrm{C}$ for $30 \mathrm{sec}$, and $72^{\circ} \mathrm{C}$ for $15 \mathrm{sec}$. U6 or GAPDH was used as the reference genes, and relative gene expression level was calculated using comparative $\mathrm{C}_{\text {quantification }}$ cycle method $\left(2^{-\Delta \Delta \mathrm{Cq}}\right)$.

Western blotting. Protein from cells was extracted using RIPA lysis buffer (Beyotime Institute of Biotechnology, Haimen, China) and concentration was measured using the BCA Protein Quantitative Assay (Beyotime Institute of Biotechnology). Total $50 \mu \mathrm{g}$ protein sample (per lane) was separated on SDS-PAGE gel, blotted onto PVDF membranes, and blocked in 5\% non-fat milk for $1 \mathrm{~h}$. The membranes were probed with mouse polyclonal antibodies to ULK1 (120 kDa; 1;1,000; ab128859; Abcam, Cambridge, UK), ALG5 (32 kDa; 1;1,000; ab108327; Abcam), Beclin-1 (52 kDa; 1;1,000; ab62557; Abcam), LC3II/LC3I (LC3-II, 17 kDa, LC3-II 19 kDa; 1;1,000; ab48394; Abcam), COL2A1 (142 kDa; 1;1,000; ab34712; Abcam), ACAN (250 kDa; 1;1,000; ab36861; Abcam), MMP-13 (54 kDa; 1;1,000; ab39012; Abcam), ADAMTS-5 (73 kDa; 1;1,000; ab41037; Abcam), SIRT1 (120 kDa; 1;1,000; ab110304; Abcam), phospho-PI3K (p-PI3K) (84 kDa; 1;1,000; ab182651; Abcam), PI3K (123 kDa; 1;1,000; ab151549; Abcam), p-AKT (65 kDa; 1;1,000; SAB4301414; Sigma-Aldrich; Merck KGaA), AKT (55 kDa; 1;1,000; SAB4500797; Sigma-Aldrich; Merck KGaA), p-mTOR (250 kDa; 1;1,000; ab137133; Abcam), mTOR (252 kDa; 1;2,000; ab2732; Abcam), and GAPDH (36 
Table I. Primer sequences for specific genes.

Gene

ULK

ALG5

Beclin-1

LC3II

COL2A1

ACAN

MMP-13

ADAMTS-5

SIRT1

GAPDH
Primer sequence

Forward: 5'-GTGCAGTCGGCTGCCCTGGAC-3'

Reverse: 5'-TCAGGCACAGATGCCAGTCAGC-3'

Forward: 5'-CATATGATGACTCGCACCCGCAAGCGCAC-3'

Reverse: 5'- AAGCTTCAGGAGTGTGTGACCTGCAGCTTG-3'

Forward: 5'- GAGGGATGGAAGGGTCTAAG-3'

Reverse: 5'-GCCTGGGCTGTGGTAAGT-3'

Forward: 5'-GATGTCCGACTTATTCGAGAGC-3'

Reverse: 5'-TTGAGCTGTAAGCGCCTTCTA-3'

Forward: 5'-GGCAATAGCAGGTTCACGTACA-3'

Reverse: 5'-GATAACAGTCTTGCCCCACTTACC-3'

Forward: 5'-AGTCCTCAAGCCTCCTGTACTCA-3'

Reverse: 5'-CGGGAAGTGGCGGTAACA-3'

Forward: 5'-CTTCTGGTCTTCTGGCACACG-3'

Reverse: 5'-CCCCACCCCATACATCTGAAA-3'

Forward: 5'-GGCGCAAATCCGGGTC-3'

Reverse: 5'-CGCCATTCACGGTGCC-3'

Forward: 5'-CAACTTGTACGACGAAGAC-3'

Reverse: 5'-TCATCACCGAACAGAAGG-3'

Forward: 5'-GAAGGTGAAGGTCGGAGTC-3'

Reverse: 5'-GAAGATGGTGATGGGATTTC-3'

ULK1, uncoordinated 51-like kinase 1; ALG5, asparagine-linked glycosylation 5; COL2A1, type II collagen; ACAN, aggrecan; MMP-13, matrix metallo protease 13; ADAMTS-5, a disintegrin and metalloproteinase with thrombospondin motifs-5; SIRT1, sirtuin type 1; GAPDH, glyceraldehyde-3-phosphate dehydrogenase.

$\mathrm{kDa} ; 1 ; 2,000$; ab8245; Abcam) overnight at $4^{\circ} \mathrm{C}$, respectively. After washed for three times with PBS, the membranes incubated with appropriate second antibody $\operatorname{IgG}(\mathrm{H}+\mathrm{L})-\mathrm{HRP}$ (125 kDa; 1:5,000; ab97051; Abcam) for $2 \mathrm{~h}$ at room temperature. Ultimately, the proteins were detected with Enhanced chemiluminescence (EMD Millipore, Billerica, MA, USA). Densitometric analysis for the protein bands was performed by Image J 1.48v (http://imagej.nih.gov/ij/, US National Institutes of Health, Bethesda, MD, USA).

Target prediction and luciferase reporter assay. The potential target gene of miR-4262 was predicted by TargetScanHuman 7.1 (http://www.targetscan.org/vert_71/). The wildtype (WT) 3'UTR fragment of SIRT1 that can bind to miR-4262 or mutant (MUT) 3'UTR fragment was amplified from the genomic DNA and cloned into the pGL3 vector. The chondrocytes were then co-transfected with miR-4262 and luciferase reporter comprising WT or MUT 3'UTR of SIRT1 for $48 \mathrm{~h}$ using Lipofectamine ${ }^{\circledR} 2000$. The Dual Luciferase Assay kit (Promega Corporation,) was used to measure the activity of luciferase.

Statistical analysis. All experiments were performed in triplicate. Statistical analysis was carried out using statistical analysis software (SPSS 19.0; SPSS, Inc., Chicago, IL, USA). Data were expressed as the mean \pm standard deviation and analyzed by one-way analysis of variance. $\mathrm{P}<0.05$ was considered to indicate a statistically significant difference.

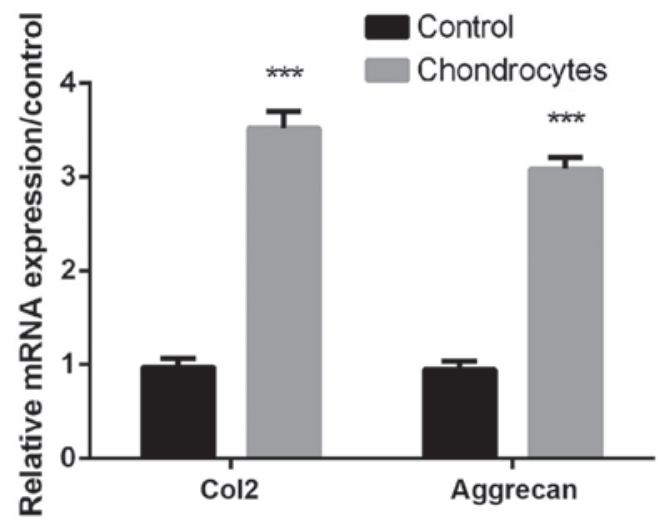

Figure 1. The expression of collagen type 2(Col2) and aggrecan was upregulated in chondrocytes compared with control. Three independent experiments were performed, and ${ }^{* * *} \mathrm{P}<0.001$ compared with the control group.

\section{Results}

Primary chondrocytes were successfully isolated. As shown in Fig. 1, the expression levels of Col2 and aggrecan in chondrocytes were significantly higher than controls (all $\mathrm{P}<0.01$, Fig. 1), indicating that Primary chondrocytes were successfully isolated for subsequent treatments.

TNF- $\alpha$ decreases cell viability and autophagy, and increases apoptosis and miR-4262 level in chondrocytes. Compared 

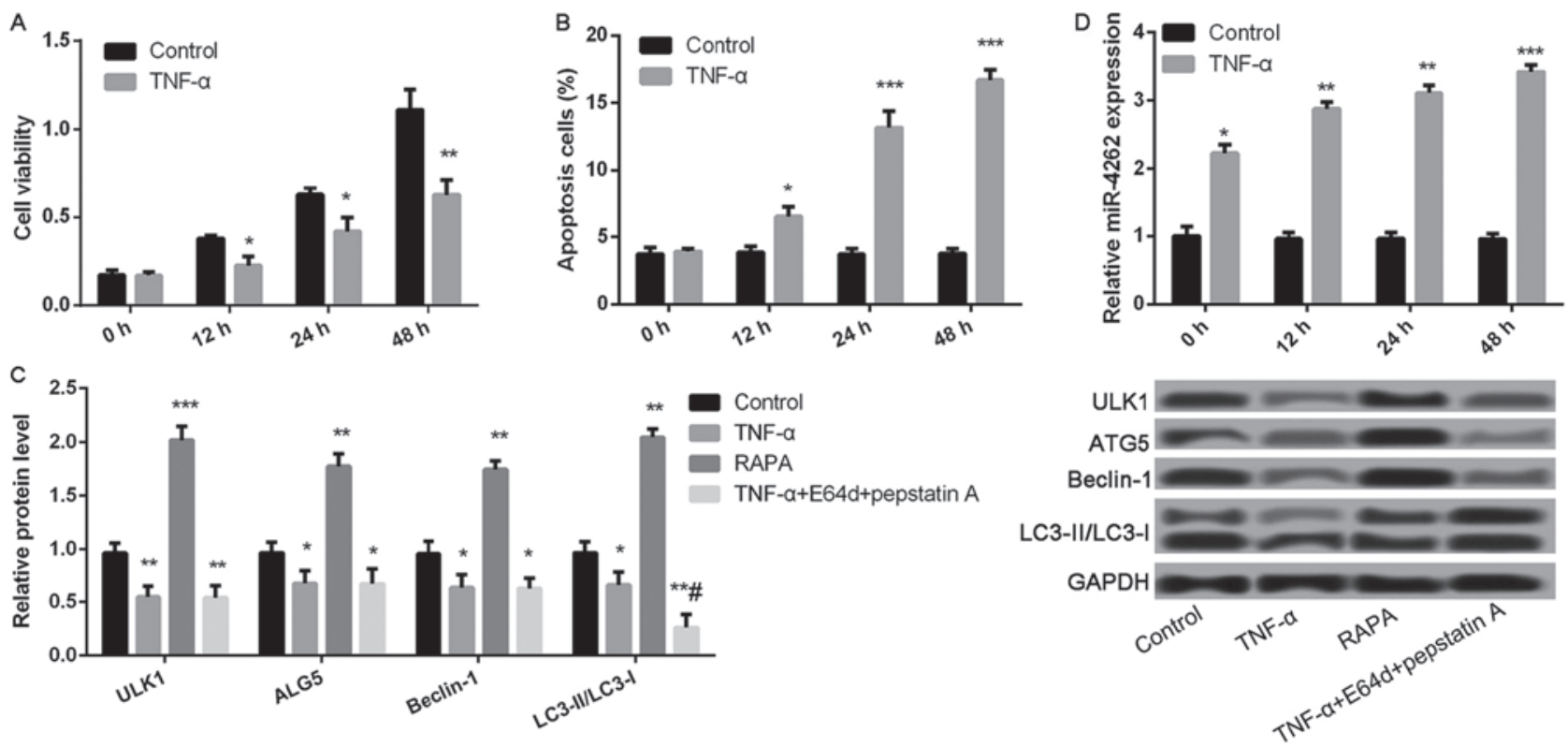

Figure 2. TNF- $\alpha$ treatment significantly decreases cell viability and autophagy, as well as increases apoptosis and the expression of miR-4262 in chondrocytes. (A) The cell viability in control and TNF- $\alpha$ groups at $0,12,24,48 \mathrm{~h}$ using CCK-8; (B) The cell apoptosis in control and TNF- $\alpha$ groups at 0 , $12,24,48 \mathrm{~h}$ using TUNEL staining; (C) The expression of autophagy-related proteins, including ULK1, ALG5, Beclin-1, LC3II/LC3I, in control, TNF- $\alpha$, RAPA and TNF- $\alpha+$ E64d + pepstatin A groups using western blotting; (D) The level of miR-4262 in control and TNF- $\alpha$ groups at 0, 12, 24, 48 h using quantitative reverse transcription PCR. Three independent experiments were performed in each assay. ${ }^{*} \mathrm{P}<0.05,{ }^{* *} \mathrm{P}<0.01$, and ${ }^{* * * *} \mathrm{P}<0.001$ compared with the control group, ${ }^{\#} \mathrm{P}<0.05$ compared with the TNF- $\alpha$ group. TNF- $\alpha$, tumor necrosis factor- $\alpha$; RAPA, rapamycin; ULK1, uncoordinated 51-like kinase 1; ALG5, asparagine-linked glycosylation 5 .

with control, cell viability was significantly inhibited, while the ratio of cell apoptosis was markedly increased after treatment with TNF- $\alpha$ for 12,24 , and $48 \mathrm{~h}$ (all $\mathrm{P}<0.05$, Fig. 2A and B). Compared with control group, the expression levels of autophagy-related proteins, including ULK1, ALG5, Beclin-1, and LC3II/LC3I, were remarkably lower in TNF-agroup, while significantly increased in RAPA group (all $\mathrm{P}<0.05$, Fig. 2C). Nevertheless, only the expression ratio of LC3II/LC3I was significantly decreased in TNF- $\alpha$-treated cells after treatment with lysosomal protease inhibitors E64d and pepstatin $\mathrm{A}(\mathrm{P}<0.05$, Fig. $2 \mathrm{C})$, but not the expression levels of ULK1, ALG5, and Beclin-1. In addition, TNF- $\alpha$ treatment significantly increased miR-4262 level compared with control (all $\mathrm{P}<0.05$, Fig. 2D).

Overexpression of miR-4262 inhibits cell viability, autophagy, and matrix synthesis, and promoted cell apoptosis in chondrocytes. As shown in Fig. 3A, the miR-4262 level was significantly increased in cells with miR-4262 mimic compared with cells with mimic control $(\mathrm{P}<0.001)$, and the transfection of miR-4262 inhibitor obviously inhibited the miR-4262 level compared with the transfection of inhibitor control $(\mathrm{P}<0.01)$. Moreover, compared with mimic control, cell viability was significantly inhibited in miR-4262 mimic group, while the percentage of apoptotic cells was obviously increased (all $\mathrm{P}<0.05$, Fig. 3B and $\mathrm{C}$ ). The expression levels of autophagy-related proteins, including ULK1, ALG5, Beclin-1, and LC3II/LC3I, were all significantly decreased in miR-4262 mimic group compared with mimic control group (all $\mathrm{P}<0.05$, Fig. 3D). Opposite effects on cell viability, apoptosis and autophagy were obtained after transfection with miR-4262 inhibitor (all $\mathrm{P}<0.05$, Fig. 3B-D). Furthermore, the results revealed that, compared with TNF- $\alpha+$ mimic control group, cell viability was significantly inhibited in cells with the treatments of TNF- $\alpha$ and miR-4262, while the ratio of cell apoptosis was markedly increased (all $\mathrm{P}<0.05$, Fig. $3 \mathrm{E}$ and $\mathrm{F}$ ). The expression levels of autophagy-related proteins, including ULK1, ALG5, Beclin-1, and LC3II/LC3I, were all remarkably lower expressed in cells with the treatments of TNF- $\alpha$ and miR-4262 (all P<0.01, Fig. 3G). Notably, compared with TNF- $\alpha$-treated cells, the expression ratio of LC3II/LC3I was further decreased after treatment with lysosomal protease inhibitors E64d and pepstatin A ( $\mathrm{P}<0.05$, Fig. 3G). In addition, we detect the expression of matrix synthesis-related proteins, such as COL2A1, ACAN, MMP-13 and ADAMTS-5. The results showed, compared with TNF- $\alpha+$ mimic control group, that the protein levels of COL2A1 and ACAN were significantly reduced in cells with the treatments of TNF- $\alpha$ and miR-4262, while MMP-13 and ADAMTS-5 levels were remarkably increased (all $\mathrm{P}<0.01$, Fig. $3 \mathrm{H}$ ). Consistently, cells with the treatments of TNF- $\alpha$ and miR-4262 inhibitor exhibited the opposite effects on cell viability, cell apoptosis, cell autophagy, and matrix synthesis in chondrocytes (all $\mathrm{P}<0.05$, Fig. $3 \mathrm{E}-\mathrm{H}$ ).

SIRT1 is confirmed as a direct target of miR-4262. Sequence analysis with TargetScanHuman revealed that SIRT1 was a potential target gene of miR-4262 (http://www.targetscan . org/cgi-bin/targetscan/vert_71/view_gene.cgi?rs= ENST00000212015.6\&taxid $=9606 \&$ members $=$ miR $-181-5 p$ $\&$ showcnc $=0 \&$ shownc $=0 \&$ shownc_nc $=\&$ showncf 1 $=\&$ showncf $2=\&$ subset=1; Fig. 4A). Then luciferase reporter assay showed that miR-4262 mimic significantly inhibited the luciferase activity of WT 3'UTR of SIRT1 $(\mathrm{P}<0.05)$ but not MUT 3'UTR of SIRT1 compared with control (Fig. 4B). In 

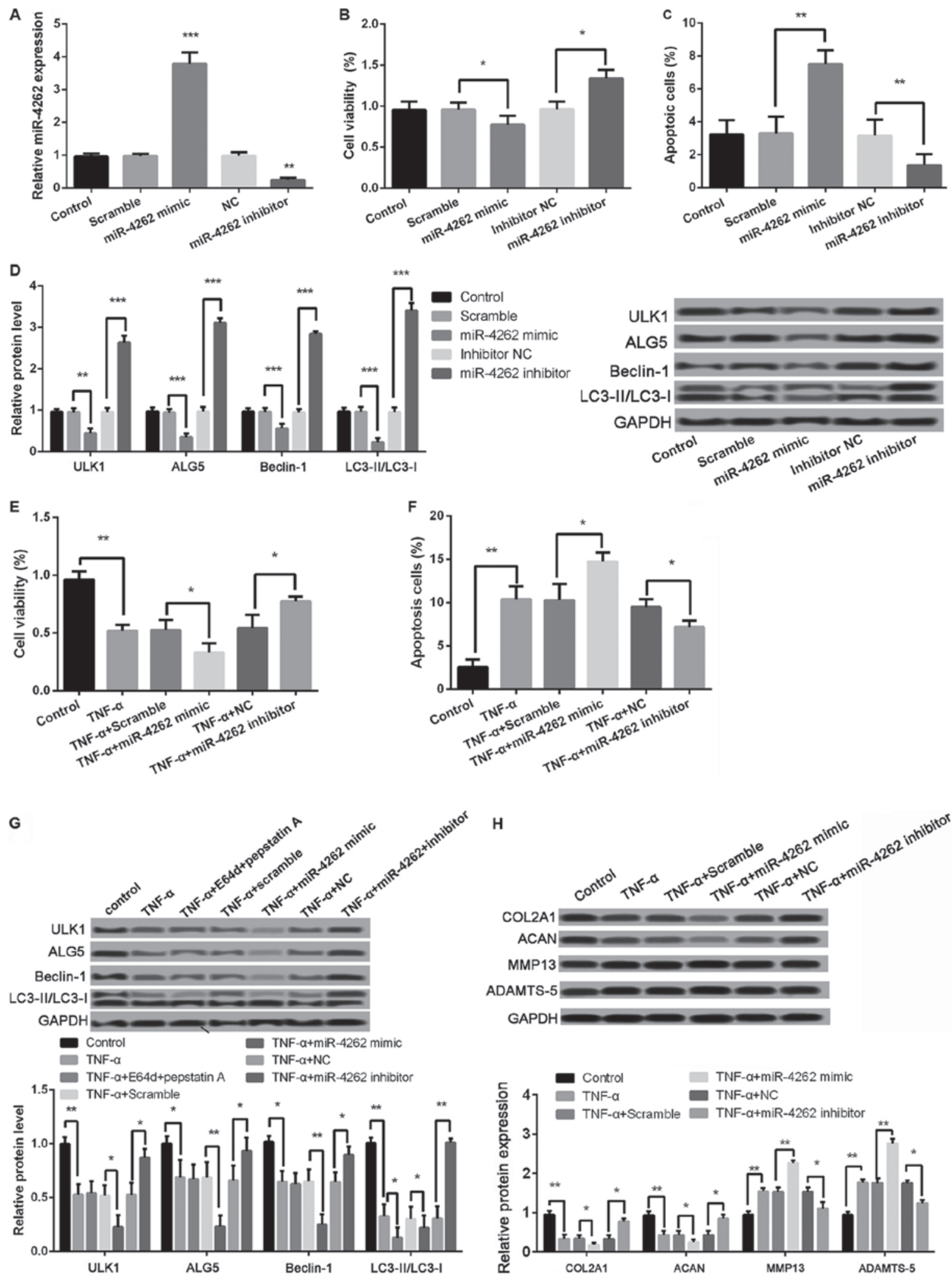

Figure 3. Upregulated miR-4262 further decreases cell viability, autophagy, and matrix synthesis as well as increases apoptosis in TNF- $\alpha$-treated chondrocytes. (A) The miR-4262 level in control, scramble (control of mimic), miR-4262 mimic, NC (control of inhibitor), and miR-4262 inhibitor groups by qPCR; (B) The cell viability in control, scramble, miR-4262 mimic, inhibitor NC, and miR-4262 inhibitor groups using CCK-8; (C) The cell apoptosis in control, scramble, miR-4262 mimic, inhibitor NC, and miR-4262 inhibitor groups using TUNEL staining; (D) The expression of autophagy-related proteins, including ULK1, ALG5, Beclin-1, LC3II/LC3I, in control, scramble, miR-4262 mimic, inhibitor NC, and miR-4262 inhibitor groups using western blotting; (E) The cell viability in control, TNF- $\alpha$, TNF- $\alpha+$ scramble, TNF- $\alpha+$ miR-4262 mimic, TNF- $\alpha+$ NC, and TNF- $\alpha+$ miR-4262 inhibitor groups using CCK-8; (F) The cell apoptosis in control, TNF- $\alpha$, TNF- $\alpha+$ scramble, TNF- $\alpha+$ miR-4262 mimic, TNF- $\alpha+$ NC, and TNF- $\alpha+$ miR-4262 inhibitor groups using TUNEL staining; (G) The expression of autophagy-related proteins, including ULK1, ALG5, Beclin-1, LC3II/LC3I, in control, TNF- $\alpha$, TNF- $\alpha+E 64 \mathrm{~d}+$ pepstatin (A) TNF- $\alpha+$ scramble, TNF- $\alpha+$ miR-4262 mimic, TNF- $\alpha+$ NC, and TNF- $\alpha+$ miR-4262 inhibitor groups using western blotting; $(\mathrm{H})$ The expression of matrix synthesis-related proteins, such as COL2A1, ACAN, MMP-13 and ADAMTS-5, in control, TNF- $\alpha$, TNF- $\alpha+$ scramble, TNF- $\alpha+$ miR-4262 mimic, TNF- $\alpha+$ NC, and TNF- $\alpha+$ miR-4262 inhibitor groups using western blotting. Three independent experiments were performed in each assay. ${ }^{*} \mathrm{P}<0.05,{ }^{* * *} \mathrm{P}<0.01$, and ${ }^{* * * *} \mathrm{P}<0.001 \mathrm{TNF}-\alpha$, tumor necrosis factor- $\alpha$; ULK1, uncoordinated 51-like kinase 1; ALG5, asparagine-linked glycosylation 5; COL2A1, type II collagen; ACAN, aggrecan; MMP-13, matrix metallo protease 13; ADAMTS-5, a disintegrin and metalloproteinase with thrombospondin motifs-5. 


\section{A}

Position 63-69 of SIRT1 3'-UTR 5'-UGUCAAAAUGAAUGUU-3'

hsa-miR-4262

B

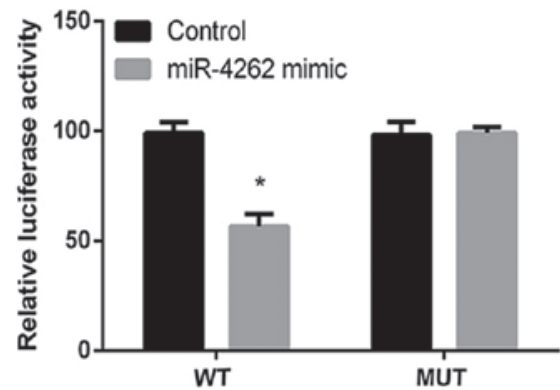
3'-UCCAUCAGACUUACAG-5'
Predicted consequential pairing of target region (top) and miRNA (bottom)

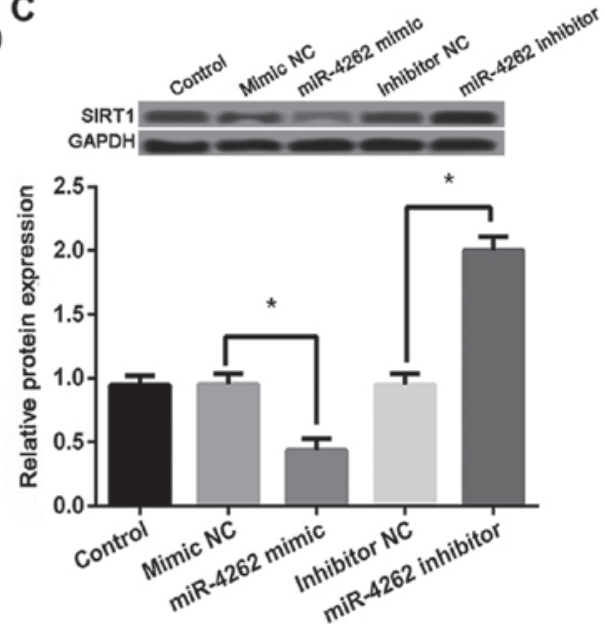

Figure 4. SIRT1 may be a potential target gene of miR-4262. (A) Prediction of the target gene of miR-4262 by sequence analysis using TargetScanHuman 7.1 and the results are shown in http://www.targetscan.org/cgi-bin/targetscan/vert_71/view_gene.cgi?rs=ENST00000212015.6\&taxid=9606\&members=miR-181$5 \mathrm{p} \&$ showcnc $=0 \&$ shownc $=0 \&$ shownc_nc $=\&$ showncf $1=\&$ showncf $2=\&$ subset $=1$; (B) To verify the predicted results of TargetScanHuman, luciferase reporter assay was performed. The chondrocytes were co-transfected with miR-4262 mimic and luciferase reporter pGL3 comprising with wild type (WT) and mutant (MUT) 3'UTR SIRT1, and then the luciferase activity was detected using luciferase reporter assay; (C) To further verify the target relationship between SIRT1 and miR-4262, the SIRT1 level in control, scramble, miR-4262 mimic, inhibitor NC, and miR-4262 inhibitor groups by western blotting. Three independent experiments were performed in each assay. ${ }^{*} \mathrm{P}<0.05$; SIRT1, sirtuin type 1.

addition, compared with cells with mimic or inhibitor control, miR-4262 mimic or inhibitor obviously inhibited or increased the expression of SIRT1 ( $\mathrm{P}<0.05$, Fig. 4C). These data indicated that SIRT1 was a target of miR-4262 and its expression was negatively regulated by miR-4262.

Overexpression of SIRT1 promotes cell viability, autophagy, and matrix synthesis, and inhibited cell apoptosis, autophagy, and matrix synthesis in chondrocytes. As shown in Fig. 5A and $\mathrm{B}$, the protein and mRNA levels of SIRT1 were significantly increased in cells with pEX-SIRT1 compared with cells with pEX $(\mathrm{P}<0.001)$, and the transfection of sh-SIRT1 obviously inhibited the SIRT1 level compared with the transfection of siNC $(\mathrm{P}<0.05)$. In addition, compared with TNF- $\alpha+\mathrm{pEX}$ treated cells, cell viability was significantly increased, while the ratio of cell apoptosis was obviously inhibited in cells with the treatments of TNF- $\alpha$ and pEX-SIRT1 (all $\mathrm{P}<0.05$, Fig. 5C and D). The expression levels of autophagy-related proteins, including ULK1, ALG5, Beclin-1, and LC3II/LC3I, were all remarkably increased in cells with the treatments of TNF- $\alpha$ and pEX-SIRT1 (all P<0.01, Fig. 5E) compared with TNF- $\alpha+$ pEX treated cells. In addition, the protein levels of COL2A1 and ACAN were significantly increased, while MMP-13 and ADAMTS-5 levels were remarkably reduced in cells with the treatments of TNF- $\alpha$ and pEX-SIRT1 (all $\mathrm{P}<0.01$, Fig. 5F) compared with TNF- $\alpha+$ pEX treated cells. Consistently, cells with the treatments of TNF- $\alpha$ and miR-4262 inhibitor exhibited the opposite effects on cell viability, cell apoptosis, cell autophagy, and matrix synthesis in chondrocytes (all $\mathrm{P}<0.05$, Fig. 3E-H). Consistently, cells with the treatments of TNF- $\alpha$ and sh-SIRT1 exhibited the opposite effects on cell viability, cell apoptosis, cell autophagy, and matrix synthesis in chondrocytes (all $\mathrm{P}<0.05$, Fig. 5C and D).

Roles of miR-4262 in chondrocytes are associated with the regulation of SIRTI. The results revealed that compared with cells with TNF- $\alpha$, miR-4262 mimic and pEX, cell viability was significantly increased, while the ratio of cell apoptosis was obviously inhibited in cells with the treatments of TNF- $\alpha$, miR-4262 mimic and pEX-SIRT1 (all P<0.05, Fig. 6A and B). The expression levels of autophagy-related proteins, including ULK1, ALG5, Beclin-1, and LC3II/LC3I, were all remarkably higher expressed in cells with the co-treatments of TNF- $\alpha$, miR-4262 mimic and pEX-SIRT1 than those in cells with TNF- $\alpha$, miR-4262 mimic and pEX (all $\mathrm{P}<0.05$, Fig. 6C). In addition, protein levels of COL2A1 and ACAN were significantly increased, while MMP-13 and ADAMTS-5 levels were remarkably reduced in cells with the co-treatments of TNF- $\alpha$, miR-4262 mimic and pEX-SIRT1 compared with cells with TNF- $\alpha$, miR-4262 mimic and pEX (all P<0.01, Fig. 6D).

Overexpression of miR-4262 activates PI3K/AKT/mTOR signaling pathway. Compared with untreated cells, the expression levels of p-PI3K, p-AKT, and p-mTOR was significantly increased in TNF- $\alpha$ treated cells, and the co-treatments of TNF- $\alpha$ and miR-4262 mimic further increased the expression levels of p-PI3K, p-AKT, and p-mTOR (all P<0.05, Fig. 7). In addition, cells with TNF- $\alpha$, miR-4262 mimic and pEX-SIRT1 exhibited lower levels of p-PI3K, p-AKT, and p-mTOR than those in cells with TNF- $\alpha$, miR-4262 mimic and pEX (all P<0.05, Fig. 7).

\section{Discussion}

In the current study, our results showed that TNF- $\alpha$ could inhibit cell viability and the expression levels of autophagy-related proteins as well as increase cell apoptosis in rat chondrocytes. Overexpressed miR-4262 further promoted the cell injury induced by TNF- $\alpha$, while its target gene SIRT1 could alleviate the cell injury by promoting cell viability and the expression levels of autophagy-related proteins, as well as inhibiting cell apoptosis in TNF- $\alpha$-treated chondrocytes. In addition, miR-4262 influenced the expression levels of 
A
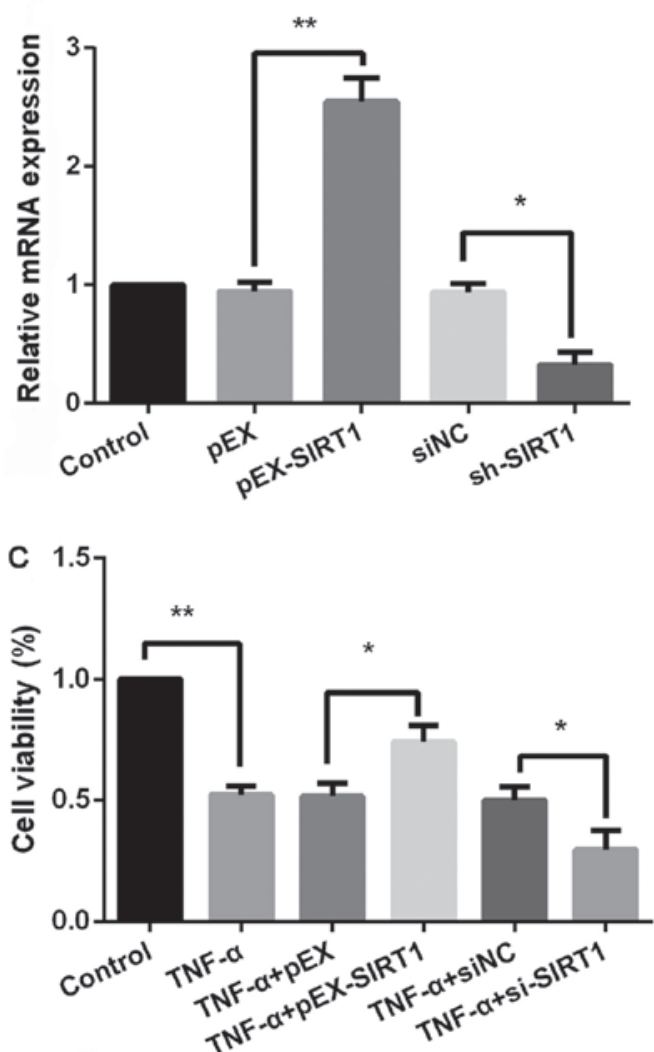

E

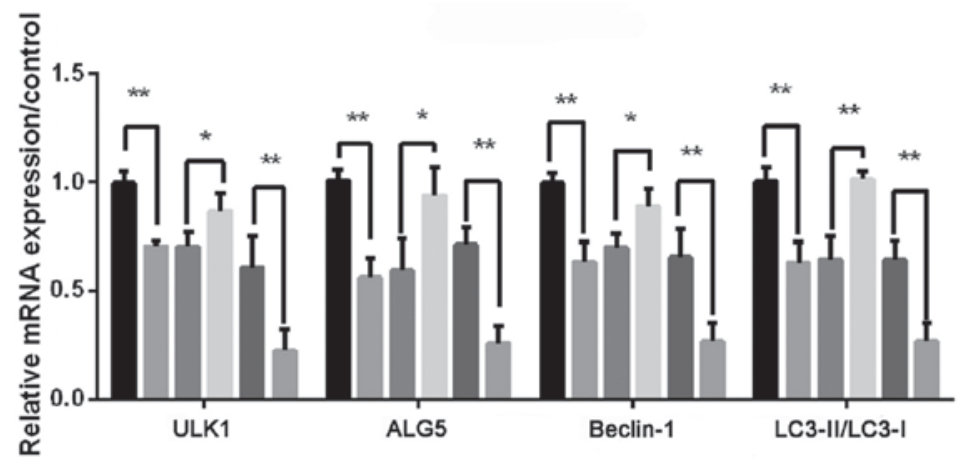

F

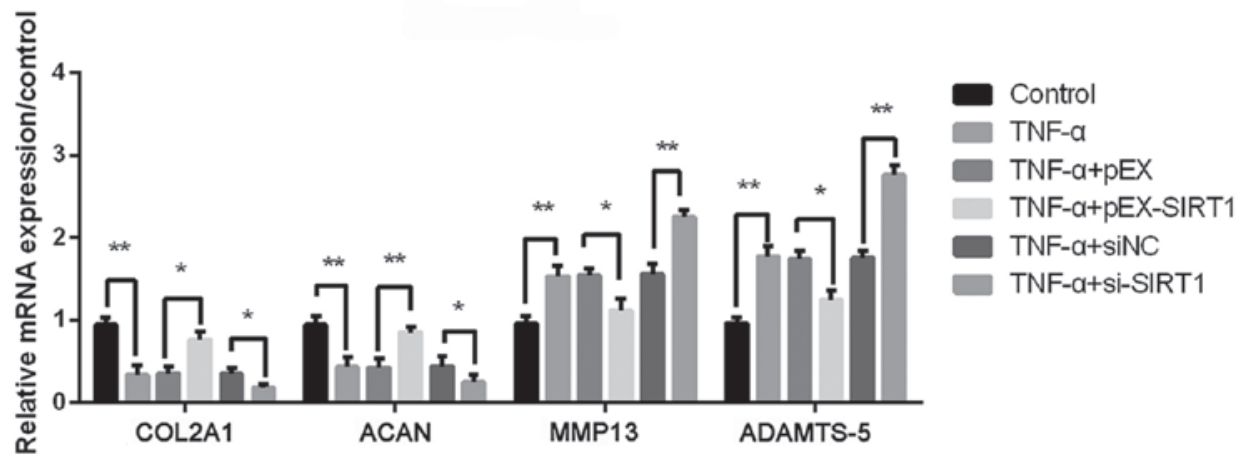

B
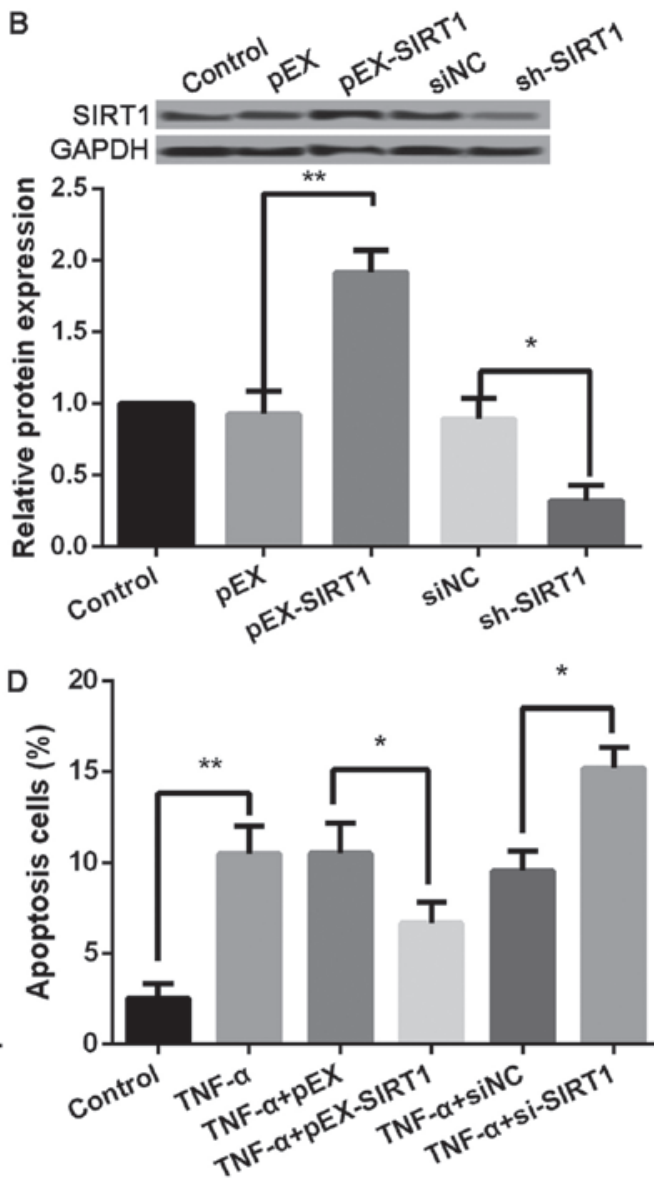

Control

TNF- $a$

TNF- $\alpha+p E X$

TNF- $a+p E X-S I R T 1$

TNF-a+siNC

TNF-a+si-SIRT1

Figure 5. Upregulated SIRT1 increases cell viability, autophagy, and matrix synthesis as well as decreases apoptosis in TNF- $\alpha$-treated chondrocytes. (A) The SIRT1 level in control, pEX, pEX-SIRT1, siNC, and si-SIRT1 groups by qPCR; (B) The SIRT1 level in control, pEX, pEX-SIRT1, siNC, and si-SIRT1 groups by western blotting; The cell viability in (C) control, TNF- $\alpha$, TNF- $\alpha+$ pEX, TNF- $\alpha+$ pEX-SIRT1, TNF- $\alpha+$ siNC, and TNF- $\alpha+$ si-SIRT1 groups using CCK-8; (D) The cell apoptosis in control, TNF- $\alpha$, TNF- $\alpha+$ pEX, TNF- $\alpha+$ pEX-SIRT1, TNF- $\alpha+$ siNC, and TNF- $\alpha+$ si-SIRT1 groups using TUNEL staining; (E) The expression of autophagy-related proteins, including ULK1, ALG5, Beclin-1, LC3II/LC3I, in control, TNF- $\alpha$, TNF- $\alpha+$ pEX, TNF- $\alpha+$ pEX-SIRT1, TNF- $\alpha+$ siNC, and TNF- $\alpha+$ si-SIRT1 groups using qPCR; (F) The expression of matrix synthesis-related proteins, such as COL2A1, ACAN, MMP-13 and ADAMTS-5, in control, TNF- $\alpha$, TNF- $\alpha+$ pEX, TNF- $\alpha+$ pEX-SIRT1, TNF- $\alpha+$ siNC, and TNF- $\alpha+$ si-SIRT1 groups using qPCR. Three independent experiments were performed in each assay. ${ }^{*} \mathrm{P}<0.05$, and ${ }^{* *} \mathrm{P}<0.01 \mathrm{TNF}-\alpha$, tumor necrosis factor- $\alpha$; ULK1, uncoordinated 51-like kinase 1; ALG5, asparagine-linked glycosylation 5; COL2A1, type II collagen; ACAN, aggrecan; MMP-13, matrix metallo protease 13; ADAMTS-5, a disintegrin and metalloproteinase with thrombospondin motifs-5; SIRT1, sirtuin type 1. 
A
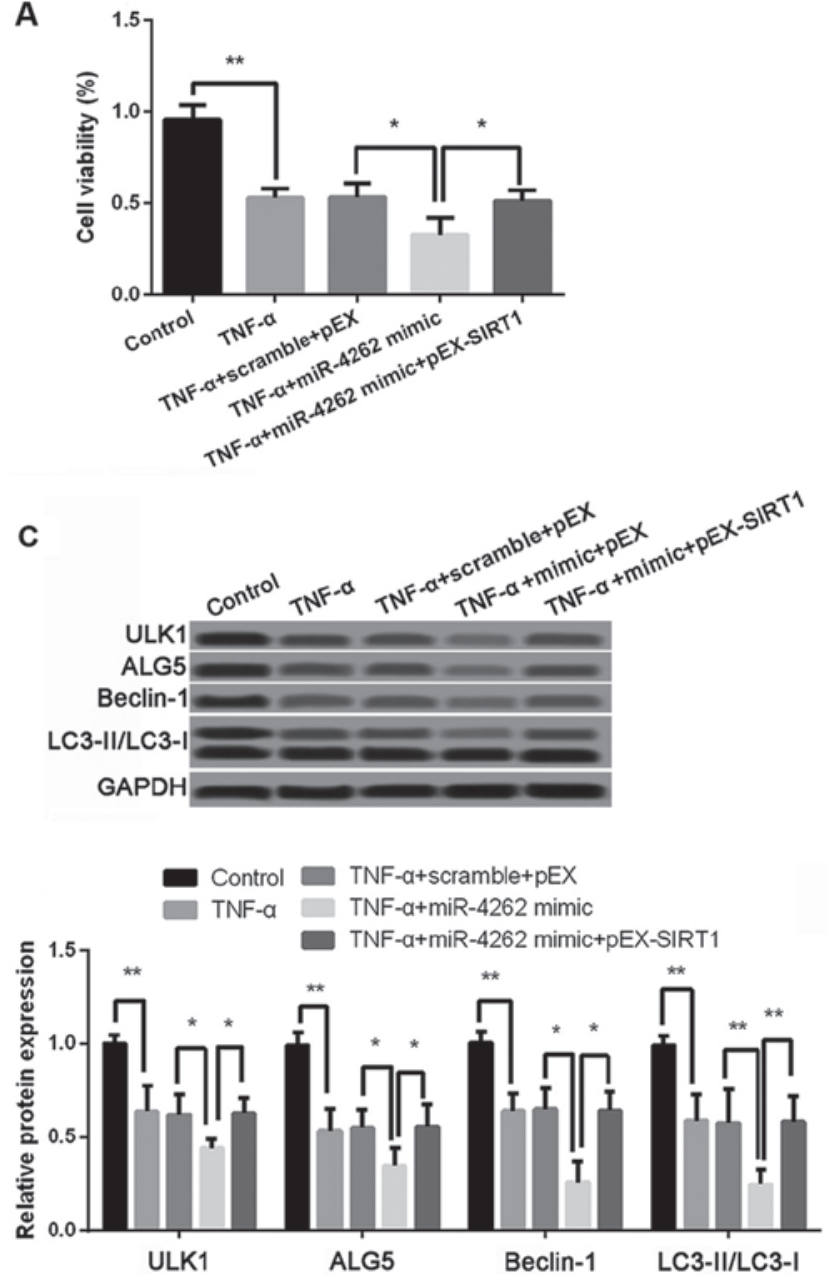

B
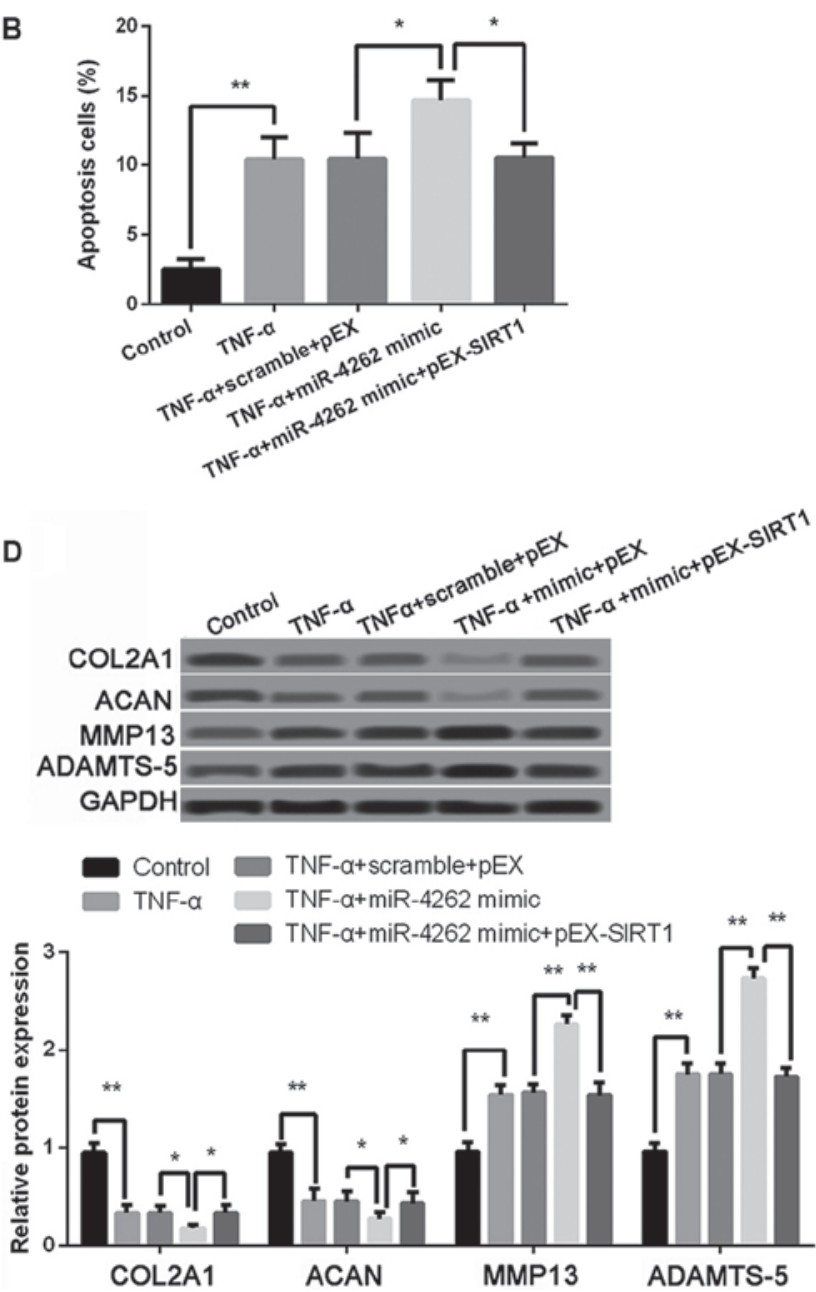

Figure 6. Effects of miR-4262 on cell viability, cell apoptosis, cell autophagy, and matrix synthesis is inhibited by SIRT1. (A) The cell viability in control, TNF- $\alpha$, TNF- $\alpha+$ scramble + pEX, TNF- $\alpha+$ miR-4262 mimic, and TNF- $\alpha+$ miR-4262 mimic + pEX-SIRT1 groups using CCK-8; (B) The cell apoptosis in control, TNF- $\alpha$, TNF- $\alpha+$ scramble + pEX, TNF- $\alpha+$ miR-4262 mimic, and TNF- $\alpha+$ miR-4262 mimic + pEX-SIRT1 groups using TUNEL staining; (C) The expression of autophagy-related proteins, including ULK1, ALG5, Beclin-1, LC3II/LC3I, in control, TNF- $\alpha$, TNF- $\alpha+$ scramble + pEX, TNF- $\alpha+$ miR-4262 mimic, and TNF- $\alpha+$ miR-4262 mimic + pEX-SIRT1 groups using western blotting; (D) The expression of matrix synthesis-related proteins, such as COL2A1, ACAN, MMP-13 and ADAMTS-5, in control, TNF- $\alpha$, TNF- $\alpha+$ scramble + pEX, TNF- $\alpha+$ miR-4262 mimic, and TNF- $\alpha+$ miR-4262 mimic + pEX-SIRT1 groups using western blotting. Three independent experiments were performed in each assay. ${ }^{*} \mathrm{P}<0.05$, and ${ }^{* *} \mathrm{P}<0.01 \mathrm{TNF}-\alpha$, tumor necrosis factor- $\alpha$; ULK1, uncoordinated 51-like kinase 1; ALG5, asparagine-linked glycosylation 5; COL2A1, type II collagen; ACAN, aggrecan; MMP-13, matrix metallo protease 13; ADAMTS-5, a disintegrin and metalloproteinase with thrombospondin motifs-5; SIRT1, sirtuin type 1.

matrix synthesis-related proteins. Furthermore, up-regulated miR-4262 remarkably increased the expression of $\mathrm{p}-\mathrm{PI} 3 \mathrm{~K}$, p-AKT and p-mTOR.

Several studies had demonstrated that miRNAs played a vital role in the regulation of the OA development, including miR-210 (21), miR-16 (22), miR-21 (23), and miR-142 (24). This study found the up-regulation of miR-4262 in TNF- $\alpha$-treated chondrocytes. Few studies had investigated the roles of miR-4262 in OA. Previous studies had revealed the proliferation promotion effect of miR-4262 overexpression in cancers, including melanoma (14), breast cancer (25), hepatocellular carcinoma (26), and osteosarcoma (16), indicating an carcinogenesis role of miR-4262. However, this study found that up-regulated miR-4262 inhibited cell viability in TNF- $\alpha$-treated chondrocytes, which might be explained that miR-4262 exerted the opposite effect on cell proliferation in cancers and non-cancers.

It was reported that $\mathrm{OA}$ is caused by the death of chondrocytes and the loss of extracellular matrix in cartilage degeneration (27). Apoptosis and autophagy are basic physiologic processes for balancing cell homeostasis and death. Apoptosis of damaged chondrocytes led to articular cartilage degeneration and subsequent OA development, while autophagy could inhibit damaged chondrocyte apoptosis and thus alleviate the progression of OA (28). In this study, up-regulated miR-4262 inhibited the expression levels of autophagy-related proteins and increased cell apoptosis in TNF- $\alpha$-treated chondrocytes. It was well-known that TNF- $\alpha$ played a vital role in the pathogenesis of OA, and participated in the progression of cartilage degeneration (29). TNF- $\alpha$ could induce articular chondrocytes death through promoting cell apoptosis and autophagy (30-32). Several studies also found that cell autophagy had a protective effect on chondrocytes by inhibiting cell death $(33,34)$. Huang et al $(35)$ demonstrated that leptin was implicated in OA pathogenesis though promoting apoptosis and inhibiting autophagy of chondrocytes. This study showed that TNF- $\alpha$ inhibited cell autophagy and increased cell apoptosis, and up-regulated 

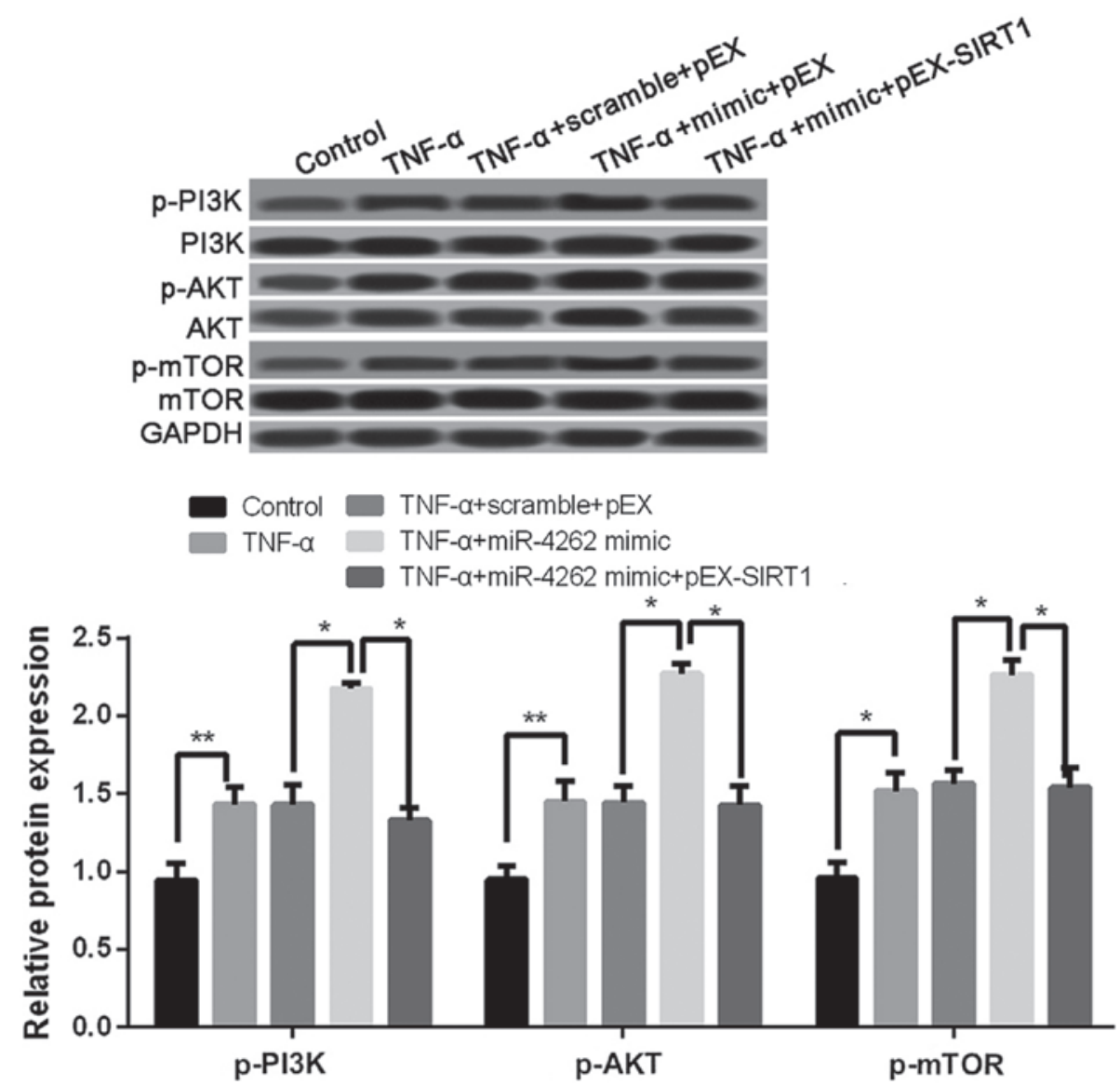

Figure 7. Upregulated miR-4262 activates PI3K/AKT/mTOR signaling pathway in TNF- $\alpha$-treated chondrocytes. The expression of p-PI3K, p-AKT, and p-mTOR in control, TNF- $\alpha$, TNF- $\alpha+$ scramble + pEX, TNF- $\alpha+$ miR-4262 mimic, and TNF- $\alpha+$ miR-4262 mimic + pEX-SIRT1 groups using western blotting. Three independent experiments were performed in each assay. ${ }^{*} \mathrm{P}<0.05$, and ${ }^{* *} \mathrm{P}<0.01$ TNF- $\alpha$, tumor necrosis factor- $\alpha$; phosphoinositide 3-kinase; phospho-PI3K (p-PI3K), PI3K; mTOR, mammalian target of rapamycin; SIRT1, sirtuin type 1.

miR-4262 enhanced these roles in TNF- $\alpha$-treated chondrocytes, implying that up-regulation of miR-4262 might contribute to OA development in rats via promoting apoptosis and inhibiting autophagy of chondrocytes. Meanwhile, this study revealed that both miR-4262 overexpression and TNF- $\alpha$ treatment inhibited the levels of COL2A1 and ACAN, while increased MMP-13 and ADAMTS-5 levels. Consistent with this study, a recent study further demonstrated that TNF- $\alpha$ also had been proved to be associated with the loss of matrix synthesis-related proteins, such as COL2A1 and ACAN, as well as the elevation of MMP-13 and ADAMTS-5 (36). All these results indicated that miR-4262 might be involved in the development of $\mathrm{OA}$ in rats through regulating cell viability, cell apoptosis, cell autophagy, and matrix synthesis in chondrocytes.

Furthermore, this study confirmed the target gene of miR-4262 was SIRT1. SIRT1 is found to exert deacetylation for target substrates, and then participate in cell survival, metabolism, and oxygen consumption. Recently, SIRT1 was proved to be down-regulated in chondrocytes from OA (37), which was consistent with our study. Previous study suggested that SIRT1 could inhibit the apoptosis of chondrocytes and increase the survival of OA (38). SIRT1 also was reported to inhibit the extracellular matrix degradation by inhibiting MMP13 production (20). Similarly, this study revealed that SIRT1 inhibited cell apoptosis and increased the extracellular matrix in TNF- $\alpha$-treated chondrocytes. Meanwhile, SIRT1 overexpression could reverse the effects of miR-4262 on TNF- $\alpha$-treated chondrocytes. The above results promoted that the role of miR-4262 in TNF- $\alpha$-treated chondrocytes might be regulated by its target gene SIRT1.

To further investigate the mechanism of miR-4262 in $\mathrm{OA}$, we focused on the PI3K/AKT/mTOR signaling pathway. $\mathrm{PI} 3 \mathrm{~K} / \mathrm{AKT} / \mathrm{mTOR}$ signaling pathway was not only involved in the regulation of inflammatory processes (39), but also regulated many normal cellular processes, such as cell proliferation and apoptosis (40). The activations of PI3K could induce the phosphorylation of AKT, and then inhibited the expressions of $\mathrm{Bcl}-2$ and $\mathrm{Bcl}-\mathrm{xL}$ (anti-apoptotic proteins), as well as Bax and Bak (pro-apoptotic proteins) (40). In addition, PI3K/Akt pathway could increase MMP levels produced by chondrocytes, while inhibition of mTOR increased cell autophagy, and then inhibit chondrocyte death (41). The present study found that that up-regulated miR-4262 increased the expressions of p-PI3K, p-AKT, and p-mTOR in TNF- $\alpha$-treated chondrocytes, while it could be reversed by SIRT1. Therefore, we speculated that the role of miR-4262 overexpression in TNF- $\alpha$-treated chondrocytes might be mediated by the activation of PI3K/AKT/mTOR signaling pathway.

In conclusion, the present study reveals that miR-4262 may promote the occurrence and development of $\mathrm{OA}$ in rats 
by regulating cell viability, cell apoptosis, cell autophagy, and matrix synthesis. Furthermore, these roles of miR-4262 may be associated with PI3K/AKT/mTOR signaling pathway.

\section{References}

1. Glynjones S, Palmer AJ, Agricola R, Price AJ, Vincent TL, Weinans H and Carr AJ: Osteoarthritis. Lancet 386: 376-387, 2015.

2. Neogi T: The epidemiology and impact of pain in osteoarthritis Osteoarthritis Cartilage 21: 1145-1153, 2013.

3. Wilkins JM, Loughlin J and Snelling SJ: Osteoarthritis genetics: Current status and future prospects. Future Rheumatol 2: 607-620, 2015.

4. Schachar R and Ogilvie-Harris D: Osteoarthritis: Joint conservation strategies. In: Osteoarthritis. Kapoor $M$ and Mahomed N (eds). Springer International Publishing, Switzerland, 2015

5. Litwic A, Edwards $\mathrm{MH}$, Dennison EM and Cooper C: Epidemiology and burden of osteoarthritis. Br Med Bull 105: 185-199, 2013.

6. Bartel DP: MicroRNAs: Genomics, biogenesis, mechanism, and function. cell 116: 281-297, 2004.

7. Kloosterman WP and Plasterk RH: The diverse functions of microRNAs in animal development and disease. Dev Cell 11: 441-450, 2006.

8. Jovanovic M and Hengartner M: miRNAs and apoptosis: RNAs to die for. Oncogene 25: 6176-6187, 2006.

9. Saito Y, Saito H, Liang G and Friedman JM: Epigenetic alterations and MicroRNA misexpression in cancer and autoimmune diseases: A critical review. Clin Rev Allergy Immunol 47 : $128-135,2014$

10. Condorelli G, Latronico MV and Cavarretta E: microRNAs in cardiovascular diseases: Current knowledge and the road ahead. J Am Coll Cardiol 63: 2177-2187, 2014.

11. Tan L, Yu JT and Tan L: Causes and consequences of MicroRNA dysregulation in neurodegenerative diseases. Mol Neurobiol 51: $1249-1262,2015$

12. Lin S and Gregory RI: MicroRNA biogenesis pathways in cancer Nat Rev Cancer 15: 321-333, 2015.

13. Ji Y,Gao F, Sun B,Hao J and Liu Z: Angiotensin-converting enzyme 2 inhibits apoptosis of pulmonary endothelial cells during acute lung injury through suppressing SMAD2 phosphorylation. Cell Physiol Biochem 35: 2203-2212, 2015.

14. Zhang D, Li Z, Zhang Y, Tu C, Huo J and Liu Y: miR-4262 promotes the proliferation of human cutaneous malignant melanoma cells through KLF6-mediated EGFR inactivation and p21 upregulation. Oncol Rep 36: 3657-3663, 2016.

15. Lu S, Wu J, Gao Y, Han G, Ding W and Huang X: MicroRNA-4262 activates the NF- $\mathrm{KB}$ and enhances the proliferation of hepatocellular carcinoma cells. Int J Biol Macromol 86: 43-49, 2016.

16. Song K, Liu N, Yang Y and Qiu X: Regulation of osteosarcoma cell invasion through osteopontin modification by miR-4262 Tumour Biol 37: 6493-6499, 2016.

17. Fujita N, Matsushita T, Ishida K, Kubo S, Matsumoto T, Takayama K, Kurosaka M and Kuroda R: Potential involvement of SIRT1 in the pathogenesis of osteoarthritis through the modulation of chondrocyte gene expressions. J Orthop Res 29 $511-515,2011$

18. Takayama K, Ishida K, Matsushita T, Fujita N, Hayashi S, Sasaki K, Tei K, Kubo S, Matsumoto T, Fujioka H, et al: SIRT1 regulation of apoptosis of human chondrocytes. Arthritis Rheum 60: 2731-2740, 2009.

19. Matsuzaki T, Matsushita T, Takayama K, Matsumoto $\mathrm{T}$, Nishida K, Kuroda R and Kurosaka M: Disruption of Sirt1 in chondrocytes causes accelerated progression of osteoarthritis under mechanical stress and during ageing in mice. Ann Rheum Dis 73: 1397-1404, 2014.

20. Moon MH, Jeong JK, Lee YJ, Seol JW, Jackson CJ and Park SY: SIRT1, a class III histone deacetylase, regulates TNF- $\alpha$-induced inflammation in human chondrocytes. Osteoarthritis Cartilage 21: 470-480, 2013.

21. Zhang D, Cao X, Li J and Zhao G: MiR-210 inhibits NF-кB signaling pathway by targeting DR6 in osteoarthritis. Sci Rep 5: 12775,2015 .
22. Li L, Jia J, Liu X, Yang S, Ye S, Yang W and Zhang Y: MicroRNA-16-5p controls development of osteoarthritis by targeting SMAD3 in chondrocytes. Curr Pharm Des 21: 5160-5167, 2015

23. Zhang Y, Jie J, Yang S, Liu X, Ye S and Tian H: MicroRNA-21 controls the development of osteoarthritis by targeting GDF-5 in chondrocytes. Exp Mol Med 46: e79, 2014.

24. Wang $\mathrm{X}$, Guo $\mathrm{Y}$, Wang $\mathrm{C}, \mathrm{Yu} \mathrm{H}, \mathrm{Yu} \mathrm{X}$ and $\mathrm{Yu} \mathrm{H}$. MicroRNA-142-3p inhibits chondrocyte apoptosis and inflammation in osteoarthritis by targeting HMGB1. Inflammation 39: 1718-1728, 2016.

25. Wang K, Ren Y, Liu Y, Zhang J and He JJ: miR-4262 promotes proliferation and invasion of human breast cancer cells through directly targeting KLF6 and KLF15. Oncol Res 25: 277-283, 2017.

26. Hu W, Xiao L, Cao C, Hua S and Wu D: UBE2T promotes nasopharyngeal carcinoma cell proliferation, invasion, and metastasis by activating the AKT/GSK3// $\beta$-catenin pathway. Oncotarget 7: 15161-15172, 2016

27. Almonte-Becerril M, Navarro-Garcia F, Gonzalez-Robles A, Vega-Lopez MA, Lavalle C and Kouri JB: Cell death of chondrocytes is a combination between apoptosis and autophagy during the pathogenesis of Osteoarthritis within an experimental model. Apoptosis 15: 631-638, 2010.

28. Liu LG, Xu C and YilihamuT: Autophagy genes associated with chondrocyte apoptosis: protection and balancing effects. Chin J Tissue Eng Res 19: 3231-3235, 2015 (In Chinese).

29. Kapoor M, Martelpelletier J, Lajeunesse D, Pelletier JP and Fahmi H: Role of proinflammatory cytokines in the pathophysiology of osteoarthritis. Nat Rev Rheumatol 7: 33-42, 2011.

30. Aizawa T, Kon T, Einhorn TA and Gerstenfeld LC: Induction of apoptosis in chondrocytes by tumor necrosis factor-alpha. J Orthop Res 19: 785-796, 2001.

31. Stanic I, Facchini A, Borzì RM, Vitellozzi R, Stefanelli C, Goldring MB, Guarnieri C, Facchini A and Flamigni F: Polyamine depletion inhibits apoptosis following blocking of survival pathways in human chondrocytes stimulated by tumor necrosis factor-alpha. J Cell Physiol 206: 138-146, 2006.

32. Lee SW, Song YS, Lee SY, Yoon YG, Lee SH, Park BS, Yun I, Choi H, Kim K, Chung WT and Yoo YH: Downregulation of protein kinase CK2 activity facilitates tumor necrosis factor- $\alpha$-mediated chondrocyte death through apoptosis and autophagy. PLoS One 6: e19163, 2011.

33. Bohensky J, Shapiro IM, Leshinsky S, Watanabe H and Srinivas V: PIM-2 is an independent regulator of chondrocyte survival and autophagy in the epiphyseal growth plate. J Cell Physiol 213: 246-251, 2007.

34. Bohensky J, Shapiro IM, Leshinsky S, Terkhorn SP, Adams CS and Srinivas V: HIF-1 regulation of chondrocyte apoptosis: Induction of the autophagic pathway. Autophagy 3: 207-214, 2007.

35. Huang ZM, Du SH, Huang LG, Li JH, Xiao L and Tong P: Leptin promotes apoptosis and inhibits autophagy of chondrocytes through upregulating lysyl oxidase-like 3 during osteoarthritis pathogenesis. Osteoarthritis Cartilage 24: 1246-1253, 2016.

36. Goldring MB: Molecular regulation of the chondrocyte phenotype. J Musculoskelet Neuronal Interact 2: 517-520, 2002.

37. Dvir-Ginzberg M, Gagarina V, Lee EJ and Hall DJ: Regulation of cartilage-specific gene expression in human chondrocytes by SirT1 and nicotinamide phosphoribosyltransferase. J Biol Chem 283: 36300-36310, 2008

38. Gagarina V, Gabay O, Dvir-Ginzberg M, Lee EJ, Brady JK, Quon MJ and Hall DJ: SirT1 enhances survival of human osteoarthritic chondrocytes by repressing protein tyrosine phosphatase 1B and activating the insulin-like growth factor receptor pathway. Arthritis Rheum 62: 1383-1392, 2010.

39. Xu CQ, Liu BJ, Wu JF, Xu YC, Duan XH, Cao YX and Dong JC: Icariin attenuates LPS-induced acute inflammatory responses: Involvement of PI3K/Akt and NF-kappaB signaling pathway. Eur J Pharmacol 642: 146-153, 2010.

40. Luo J, Manning BD and Cantley LC: Targeting the PI3K-Akt pathway in human cancer: Rationale and promise. Cancer Cell 4: 257-262, 2003

41. Chen J, Crawford R and Xiao Y: Vertical inhibition of the $\mathrm{PI} 3 \mathrm{~K} / \mathrm{Akt} / \mathrm{mTOR}$ pathway for the treatment of osteoarthritis. J Cell Biochem 114: 245-249, 2013. 